\section{Panel needed to combat research fraud}

Bryan Christie Edinburgh

A national panel is needed in Britain to provide advice and assistance on dealing with the problem of misconduct in bioconference has concluded.

The conference called for a meeting to be held between the General Medical Council, the and the Faculty of Pharmaceutical Medicine to determine the precise role of the proposed new body.

The two day conference, held at the Royal College of Physicians of Edinburgh, heard that Britain is 20 years behind countries such as the United States, Sweden, and Denmark in addressing the issue. medical research, a consensus three royal colleges of physicians,
A series of high profile cases in Britain, including that of $\mathrm{Dr}$ Malcolm Pearce, who falsely claimed in 1995 to have carried out the first ever relocation of an ectopic pregnancy, has intensified the need to develop better mechanisms for dealing with the problem.

The covert nature of research misconduct means that no one knows with any certainty how widespread the problem is, but the conference was provided with some worrying findings.

A survey carried out among medical students found that $36 \%$ said that they would be prepared to cheat in exams, falsify patient information, plagiarise other people's work, or forge signatures.

The conference was warned, however, that heavy handed attempts to tackle this sort of problem could end up stifling research and would result in the creation of an even bigger problem. It concluded that the best answer lies in trying to prevent the problem occurring in the first place, rather than trying to police it once fraud, dishonesty, or deception has taken place. Prevention could be achieved by improving the conduct of research through better training, education, and supervision.

At the same time, the consensus statement said that all allegations of research misconduct should be investigated "firmly, fairly and expeditiously," and better support should be provided for whistleblowers.

The conference was supported by most of the leading medical organisations in the United Kingdom, and the chairman of the organising committee, Professor Walter Nimmo, said that it was the first time the issue had been examined in such detail in an open meeting.

He said that the final outcome provides an authoritative view on how the issue can be taken forward.

The consensus statement is available at www.bmj.com

\section{Christmas firework "sweets" kill hundreds of children}

Claire Wallerstein Manila

Health experts in the Philippines are pleading for a ban on "watusi," a popular Christmas firework, which has caused the deaths of hundreds of children through phosphorus poisoning.

Each year dozens of young children are killed or disabled after eating the brightly coloured traditional fireworks, mistaking them for sweets.

Watusi is sold in corner shops or by street vendors for

less than one peso (1.5 p; 1 US cent) per $2-3 \mathrm{~cm}$ long stick. Made of yellow phosphorus, potassium chlorate, potassium nitrate, and trinitrotoluene, it crackles and emits a faint yellow glow when scratched along the ground.

The former health secretary, Dr Juan Flavier, who is currently chair of the Senate's health committee, has been trying to have watusi banned since 1993 .

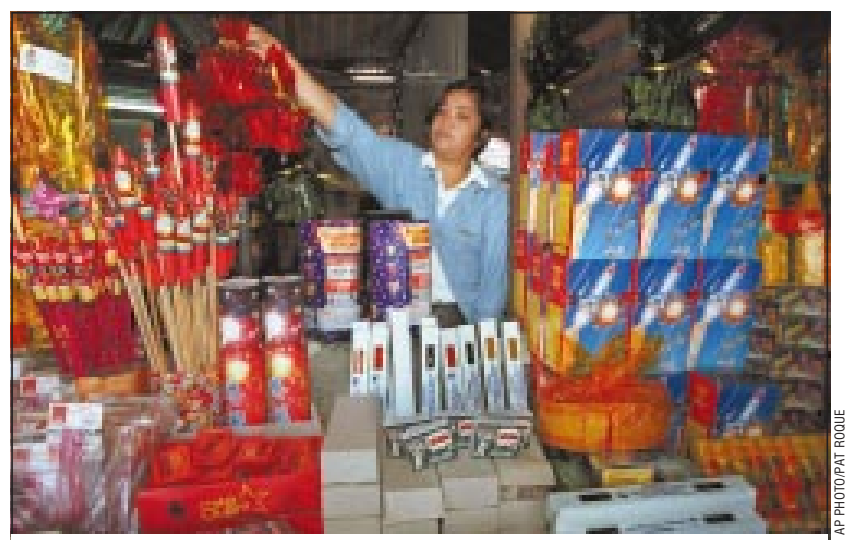

Fireworks in the Philippines: children are dying from eating "watusi," a firework that looks like a sweet
"The problem is that most of the pyrotechnics factories in the Philippines are illegal anyway," he said. "If we can't locate and regulate the firework producers, how can we control what is being sold?

"This is compounded by the fact that our politicians are reactive. They start to make a fuss over the Christmas period, when the deaths peak, but then they forget about it afterwards."

The National Poisons Control and Information Service has reported 10 cases of poisoning since January and predicts a steep rise in coming months. Most victims are toddlers who pick up the discarded ends of watusi left behind by older siblings.

Watusi is popular throughout much of the developing world, but most other countries have banned the incorporation of phosphorus, the most poisonous ingredient. Deaths have been falling in the Philippines since the discovery three years ago of an effective antidote. However, many parents still fail to bring their children to hospital until it is too late to save them.

In the absence of a ban, the Department of Health is launching an information campaign to cut the number of deaths.

\section{Council aims to integrate arts and humanities into the NHS}

Siân Knight student BMJ

The Nuffield Trust and the University of Durham are joining forces to form the United Kingdom's first national coordinating council and centre for integrating arts and humanities in the NHS.

The council hopes to encourage the health service to become more humane, empathetic, and patient friendly, mainly by bringing arts and humanities into medicine across all disciplines. Plans include encouraging the study of arts and humanities in medical schools (through intercalated degrees) and in continuing professional education.

The coordinating council will be chaired by Professor Michael Baum, professor of surgery at University College London, and is backed by several heavyweight policymakers, including Professor Sir Kenneth Calman, the former chief medical officer for England, and Sir William Reid, the former health service commissioner for England, Wales, and Scotland.

The coordinating council will be supported by a new organisation, the Centre for Arts and Humanities in Health and Medicine, which will be based at the University of Durham.

The council believes that the "arts on prescription" philosophy will lead to doctors having more depth and breadth in their education and to patients achieving mental wellbeing through creative expression.

The council is, however, eager to dismiss ideas of such treatment being disassociated from evidence based medicine.

"It is easy to dismiss this initiative as soft and flaky," said Professor Baum. "It is not. The best way of bridging the gap between arts and sciences is through medicine." (See p 1216.)

Further details of the Arts and Humanities health campaign can be found on the trust's website at www.nuffieldtrust.org.uk 